\title{
Women's role in neurosurgical research: is the gender gap improving?
}

\author{
Marta Pastor-Cabeza, MD, ${ }^{1}$ Ramon Torné, MD, PhD, ${ }^{2}$ Roser García-Armengol, MD, ${ }^{1}$ \\ Belén Menéndez-Osorio, MD, ${ }^{1}$ Alejandra Mosteiro-Cadaval, MD, ${ }^{2}$ Alicia Bollar, MD, PhD, ${ }^{3}$ \\ Jordi M. Rimbau, MD, ${ }^{1}$ Rosario Sarabia, MD, PhD, ${ }^{4}$ and Ana Rodríguez-Hernández, MD, PhD ${ }^{1}$
}

1Department of Neurosurgery, Germans Trias i Pujol University Hospital, Barcelona; ${ }^{2}$ Department of Neurosurgery, Hospital Clinic de Barcelona, Universidad de Barcelona; ${ }^{3}$ Department of Neurosurgery, Donostia University Hospital, Guipúzcoa; and ${ }^{4}$ Department of Neurosurgery, Hospital Universitario Río Hortega, Valladolid, Spain

OBJECTIVE The percentage of women publishing high-impact neurosurgical research might be perceived as a representation of our specialty and may influence the perpetuation of the existing gender gap. This study investigated whether the trend in women taking lead roles in neurosurgical research has mirrored the increase in female neurosurgeons during the past decade and whether our most prestigious publications portray enough female role models to stimulate gender diversity among the new generation of neurosurgeons.

METHODS Two of the most prominent neurosurgical journals-Journal of Neurosurgery and Neurosurgery-were selected for this study, and every original article that was published in 2009 and 2019 in each of those journals was investigated according to the gender of the first and senior authors, their academic titles, their affiliations, and their institutions' region.

RESULTS A total of 1328 articles were analyzed. The percentage of female authors was significantly higher in Europe and Russia compared with the US and Canada (first authors: $60 / 302$ [19.9\%] vs 109/829 [13.1\%], $p=0.005$; and senior authors: $32 / 302$ [10.6\%] vs $57 / 829$ [6.9\%], $p=0.040$ ). Significantly increased female authorship was observed from 2009 to 2019, and overall numbers of both first and senior female authors almost doubled. However, when analyzing by regions, female authorship increased significantly only in the US and Canada. Female authors of neurosurgical research articles were significantly less likely to hold an MD degree compared with men. Female neurosurgeons serving as senior authors were represented in only $3.6 \%(48 / 1328)$ of articles. Women serving as senior authors were more likely to have a female colleague listed as the first author of their research (29/97 [29.9\%] vs 155/1231 [12.6\%]; $\left.\chi^{2}=22.561, p=0.001\right)$.

CONCLUSIONS Although this work showed an encouraging increase in the number of women publishing high-impact neurosurgical research, the stagnant trend in Europe may suggest that a glass ceiling has been reached and further advances in equity would require more aggressive measures. The differences in the researchers' profiles (academic title and affiliation) suggest an even wider gender gap. Cultural unconscious bias may explain why female senior authors have more than double the number of women serving as their junior authors compared with men. While changes in the workforce happen, strategies such as publishing specific issues on women, encouraging female editorials, and working toward more gender-balanced editorial boards may help our journals to portray a more equitable specialty that would not discourage bright female candidates.

https://thejns.org/doi/abs/10.3171/2020.12.FOCUS20911

KEYWORDS women in neurosurgery; female neurosurgeons; neurosurgical research; publications; first author; senior author; gender gap; glass ceiling

$\mathrm{W}$ HEN neurosurgery was born as an independent specialty 100 years ago, it took more than 2 decades to witness Drs. Diana Beck, Sofia Ionescu, and Alice Rosenstein become the first recognized female neurosurgeons. ${ }^{1-3}$ The progression of women entering the neurosurgical workforce was equally slow, and it was not until around the new millennium that the overall number of female neurosurgeons started to grow significantly., ${ }^{4,5}$ Women pursuing neurosurgical residency in the US went from $10 \%$ in the late 1990 s to $17.5 \%$ in $2018 .{ }^{6}$ In Europe, a survey conducted in 2016 estimated that $32 \%$ of the neurosurgical residents were women. ${ }^{5}$ However, despite this

ABBREVIATIONS WINS = Women in Neurosurgery

SUBMITTED October 30, 2020. ACCEPTED December 21, 2020

INCLUDE WHEN CITING DOI: 10.3171/2020.12.FOCUS20911. 
encouraging recent increase in female recruitments, the specialty remains not only male-dominated, but also one of the surgical specialties with a wider gender gap and a considerable lack of women in leadership roles. ${ }^{7-9}$ With women representing more than $50 \%$ of students graduating from medical school, both in Europe and in the US, 7,10 the global percentage of fully trained female neurosurgeons (3\% in Japan, $6 \%$ in the US, and $11 \%$ in Europe) $)^{5,8,11}$ suggests the existence of significant barriers preventing gender equity in our profession. In the past decade, many have voiced a call to action to implement strategies that will help overcome those barriers. ${ }^{8,9,12,13}$ The main objective, in these authors' words, is clear: "to keep attracting the best and the brightest to neurosurgery." ",12,13 However, to plan for such strategies, gender inequalities throughout all fields of our specialty need to be tracked and their causes understood.

Research is one of the key elements that helps advance neurosurgery. In this particular field, increased gender diversity may lead to increased academic productivity and innovation, thus benefiting our specialty. ${ }^{14,15} \mathrm{~A}$ recent report about academia showed that, in general, there remains a wide gender gap favoring men in all surgical specialties; ${ }^{16}$ however, current data on academic neurosurgery are scarce, and few studies have specifically attempted to quantify the gender distribution among authors of published research. ${ }^{16-19}$ Publications in the most prestigious neurosurgical journals may serve as one measure of scholarly productivity and, therefore, may reflect the gender distribution through academic neurosurgery. Furthermore, the percentage of female investigators in such journals might be perceived as a depiction of the specialty itself, and thus, an uneven gender distribution in authorship may influence the perpetuation of gender inequity by discouraging female candidates who cannot see themselves represented.

This work was designed to better understand the recent evolution in the role of female neurosurgeons in academic publications. Ultimately, our aim was to determine whether women neurosurgeons are as likely as their male counterparts to take lead roles in academic research. Gender distribution in first authorship through some of our most prestigious journals was investigated as a likely representation of the neurosurgical workforce composition. Evolution on the number of female senior authors in those same publications was studied as an indirect representation of leadership in academic neurosurgery. We hypothesized that the recent increase in female residents has translated into a considerable increase in female first authors. But has that situation also translated into an increase in female senior authorship, or is there a glass ceiling preventing this from happening? And, equally important, do our publications portray enough female role models to stimulate gender diversity among the new generation of neurosurgeons?

\section{Methods}

Data evaluated for this study are publicly available; therefore, institutional review board approval was waived and informed consent was not required.

\section{Variables and Data Collection}

Based on their impact factors, average number of readers, widely recognized prestige, and rank within the first quartile of the specialty, ${ }^{20}$ two of the most prominent neurosurgical journals-Journal of Neurosurgery and Neurosurgery-were selected for the study. Every original article that was published in 2009 and 2019 in each of these journals was investigated. Editorials, letters to the editor, and reports from multicentric clinical trials were excluded from the analysis. For each article, we registered the type of publication (case report/video, original research, systematic review, or meta-analysis), the subspecialty classification, the gender of the first and senior authors, their academic title, their affiliation, and the region of the senior author's institution.

The last author listed in the byline was considered the senior author; however, when the corresponding author was neither the first nor the last author, he or she was considered the senior author. Whenever in doubt of whether the name corresponded to a male or a female author, an internet search was made. First, the author was searched through specific academic and professional social networks such as ResearchGate, LinkedIn, ORCID, and Academy. Second, the name was investigated in regular searching engines such as Google. Third, an email was sent to the corresponding author asking about the researcher's gender. Finally, whenever none of the above worked, the gender was considered undetermined and those articles were excluded from the analysis.

\section{Statistical Analysis}

All data were tabulated in a Microsoft Excel database, and the statistical analyses were performed using the Stata/IC version 14 software for Mac (StataCorp). Pearson's chi-square test and one-way ANOVA were used to analyze differences between gender groups and categorical variables. A p value $<0.05$ was considered statistically significant.

\section{Results}

The main results are summarized in Table 1. Of the 1429 articles that were investigated, the sex of both the first and the senior author was determined in $93.0 \%$; thus, 1328 articles were finally included in the study. Overall, $13.9 \%(184 / 1328)$ of the first authors and $7.3 \%(97 / 1328)$ of the senior authors were women. Most articles (829 [62.4\%]) were from the US and/or Canada, with Europe and Russia being the second most frequent region of the senior author's institution (302 articles [22.7\%]). The percentage of female first authors was significantly higher in Europe/Russia than in the US/Canada (60/302 [19.9\%] vs $109 / 829$ [13.1\%], $\mathrm{p}=0.005)$, and a significant difference was also found for the percentage of female senior authors $(32 / 302$ [10.6\%] vs 57/829 [6.9\%], p = 0.040). Finding a female first author was also significantly more common in articles from the US/Canada than in those from the rest of the world, excluding Europe/Russia (109/829 [13.1\%] vs $15 / 197$ [7.6\%], $\mathrm{p}=0.032$ ); however, the percentage of female senior authors in the US/Canada did not show a significant difference compared with the rest of the world, 
TABLE 1. Summary of female representation among different research publications and regions

\begin{tabular}{|c|c|c|c|c|}
\hline & \multicolumn{4}{|c|}{ No. of Authors/Total (\%) } \\
\hline & \multicolumn{2}{|c|}{2009} & \multicolumn{2}{|c|}{2019} \\
\hline & 1st Author & Senior Author & 1st Author & Senior Author \\
\hline Overall & $65 / 583(11.1)$ & $31 / 583(5.3)$ & $119 / 745(16.0)$ & $66 / 745(8.8)$ \\
\hline \multicolumn{5}{|l|}{ Type of article } \\
\hline Original article & $50 / 451(11.1)$ & $23 / 451(5.1)$ & $97 / 618(15.7)$ & $59 / 618(9.5)$ \\
\hline Review/meta-analysis & $5 / 21(23.8)$ & $0 / 21(0.0)$ & 13/61 (21.3) & $6 / 61(9.8)$ \\
\hline Case report/video & $10 / 111(9)$ & $8 / 111(7.2)$ & 9/66 (13.6) & $1 / 66(2.3)$ \\
\hline$p$ value & 0.141 & 0.366 & 0.450 & 0.089 \\
\hline \multicolumn{5}{|l|}{ Topic } \\
\hline Neurovascular & $22 / 188(11.7)$ & $13 / 188(6.9)$ & $32 / 192(16.8)$ & $11 / 192(5.7)$ \\
\hline Neurotrauma & $3 / 38(7.9)$ & $5 / 38(13.2)$ & $7 / 42(16.7)$ & $6 / 42(14.3)$ \\
\hline Pediatrics \& hydrocephalus & $1 / 21(4.7)$ & $0 / 21(0.0)$ & $5 / 36(13.9)$ & $3 / 36(8.3)$ \\
\hline Spine & $1 / 33(3)$ & $2 / 33(6.1)$ & $5 / 47(10.6)$ & $4 / 47(8.5)$ \\
\hline Functional/epilepsy & $8 / 102(7.8)$ & $4 / 102(3.9)$ & 15/98 (15.3) & $10 / 98(10.2)$ \\
\hline Tumor & $15 / 104(14.4)$ & 2/104 (1.9) & 23/167 (13.8) & $12 / 167(7.2)$ \\
\hline Skull base \& endoscopy & $2 / 37(5.4)$ & $0 / 37(0.0)$ & $4 / 45(8.9)$ & $3 / 45(6.7)$ \\
\hline Other topics & $13 / 60$ (21.7) & $5 / 60(8.3)$ & $28 / 118(23.7)$ & $17 / 118(14.4)$ \\
\hline$p$ value & 0.0057 & 0.079 & 0.267 & 0.249 \\
\hline \multicolumn{5}{|l|}{ Region } \\
\hline US \& Canada & $34 / 336(10.1)$ & $16 / 336(4.8)$ & 75/493 (15.2) & $41 / 493(8.3)$ \\
\hline Europe \& Russia & $27 / 152(17.8)$ & $12 / 152(7.9)$ & $33 / 150(22)$ & $20 / 150(13.3)$ \\
\hline Asia \& Australia & $3 / 75(4.0)$ & $2 / 75(2.7)$ & $10 / 89$ (11.2) & $3 / 89(3.4)$ \\
\hline Rest of the world & $1 / 20(5.0)$ & $1 / 20(5.0)$ & $1 / 13(7.7)$ & $2 / 13(15.4)$ \\
\hline$p$ value & 0.008 & 0.353 & 0.093 & 0.048 \\
\hline
\end{tabular}

excluding Europe/Russia (57/829 [6.9\%] vs 8/197 [4.1\%], $\mathrm{p}=0.145$ ). As shown in Table 1, female authorship was not significantly different among the various subspecialties, although the most repeated specific topic for female senior authors' publications was neurotrauma. Reviews or meta-analyses were the most common type of article found among female first authors $(18 / 82$ [22\%], $p=0.051)$.

Significantly increased female authorship was observed from 2009 to 2019, and overall numbers of both first and senior female authors almost doubled within the 10-year period (Fig. 1). In 2009, of 583 articles analyzed, 65 showed a woman as the first author, whereas in 2019, of the 745 articles analyzed, 119 showed a woman as the first author (11.1\% [65/583] vs $16.0 \%[119 / 745] ; \chi^{2}=6.376$, $\mathrm{p}=0.012$ ). In 2009, 31 female senior authors were found, and that number increased to 66 in $2019(5.3 \%$ [31/583] vs $8.9 \%$ [66/745]; $\left.\left.\chi^{2}=6.059, p=0.014\right]\right)$. Surprisingly, when analyzing these trends by region, a significant difference

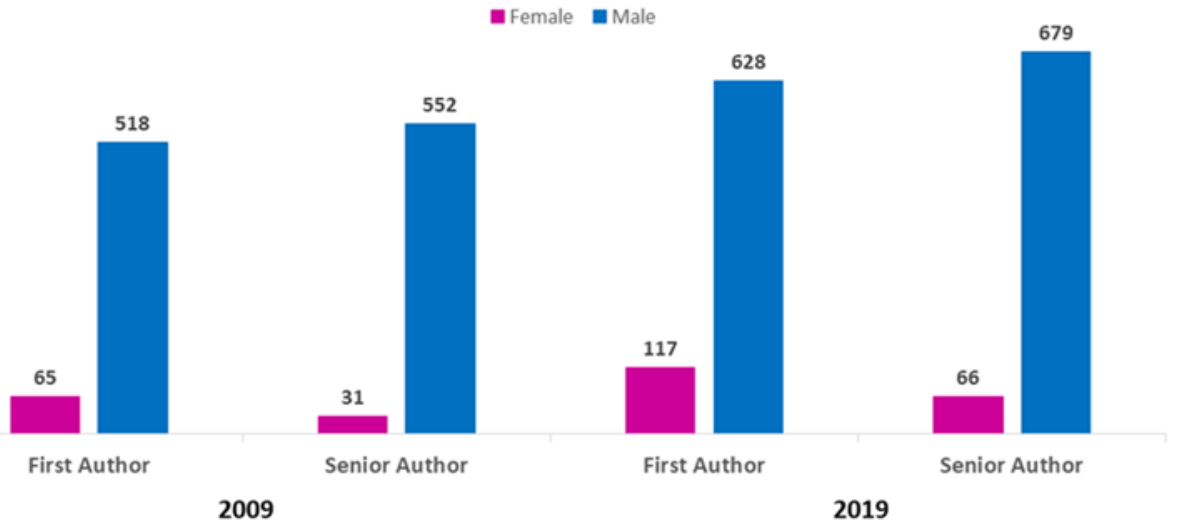

FIG. 1. Bar graph showing the gender distribution of first and senior authors in each of the study periods (horizontal axis). The vertical axis represents the overall number of individuals in each category. 
TABLE 2. Distribution of gender according to the authors' affiliation with a neurosurgical department

\begin{tabular}{lccc}
\hline & Female & Male & p Value \\
\hline 1st author & $105 / 184(57.1)$ & $922 / 1144(80.6)$ & 0.001 \\
\hline Senior author & $54 / 97(55.7)$ & $985 / 1231(80.0)$ & 0.001 \\
\hline
\end{tabular}

Values are presented as the number of authors/total number (\%) unless indicated otherwise.

was detected between the US/Canada and Europe/Russia. During the past decade, female first authorship increased significantly only in the US/Canada (34/336 [10.1\%] vs $75 / 493$ [15.2\%], $\mathrm{p}=0.033$ ); it remained stable in Europe/ Russia (33/150 [22.0\%] vs 27/152 [17.8\%], p = 0.356). Changes in senior authorship followed the same pattern, with a significant increase in the US/Canada (16/336 [4.8\%] vs 41/493 [8.3\%], $\mathrm{p}=0.047$ ) and no significant changes in Europe (12/152 [7.9\%] vs 20/150 [13.3\%], p = $0.125)$.

The data showed significantly different profiles for researchers when comparing female and male authors. Regarding the affiliation, only $57.1 \%$ (105/184) of female first authors were affiliated with a neurosurgical department, compared with 80.6\% (922/1144) of male first authors $\left(\chi^{2}=\right.$ $50.063, \mathrm{p}=0.001$ ) (Table 2). For senior authors, the difference was equally significant $\left(\chi^{2}=31.302, p=0.001\right)$. The distribution of advanced degrees was also significantly different (Table 3). Of the 281 female authors, 150 (53.4\%) held an MD degree and 38 (13.5\%) held both MD and PhD degrees. As shown in Table 3, female authors of neurosurgical research were significantly less likely to hold an MD than their male counterparts. The percentage of MDs also holding a $\mathrm{PhD}$ degree was significantly different among first authors according to gender, but that difference disappeared among senior authors. Interestingly, $76.3 \%$ of female senior authors held an MD (with or without a PhD), but fewer than half were affiliated with a neurosurgical department. Therefore, of the entire sample, female neurosurgeons served as senior authors in only $3.6 \%$ of articles (48/1328). Finally, female senior authors were more likely than their male counterparts to have a female colleague listed as the first author of their research (29/97 [29.9\%] vs $155 / 1231[12.6 \%] ; \chi^{2}=22.561, \mathrm{p}=0.001$ ).

\section{Discussion}

Using authorship of scientific publications as a surrogate marker, we aimed to investigate the gender differences in academic neurosurgery and understand the picture that our most prestigious journals display, in terms of gender distribution, to possible new recruitments. The data showed that, despite some concerning asymmetries, the overall number of women taking lead roles (first or senior/corresponding author) in neurosurgical research has significantly increased over the past decade. However, even after this encouraging improvement, the percentage of female authorship falls short of the $15 \%$ tipping point for minorities ${ }^{21}$ and is still far from an equitable situation. Furthermore, significant differences in the profiles of women and men serving as leading neurosurgical researchers may suggest an even wider gender gap than the one unveiled by the raw percentages.

\section{Role Models and Mentorship}

Academic publications have a strong influence on the visibility of women in a given field. ${ }^{22}$ The present data showed that the percentage of female authors in the most prestigious journals is only $13.8 \%$ for first/junior researchers and $7.3 \%$ for senior authors. One consequence of such a scarce number of women taking the lead in neurosurgical research is the lack of same-gender role models for medical students interested in our specialty. Several studies have demonstrated that the presence of outstanding role models and the perceived gender distribution within a specialty have a stronger influence on career choice than lifestyle issues. ${ }^{9,22-25}$ Furthermore, the number of women surgeons among medical school faculty has been directly linked to the proportion of female students choosing surgery as their career path..$^{23,26,27}$ Specifically in academic neurosurgery, Sarkiss et al. showed that residents' publications in the US correlated with their faculty productivity and suggested that the exposure to excellent role models was one of the causes. ${ }^{28}$ Moreover, a survey conducted among European neurosurgeons determined that women strive to identify with same-gender role models; ${ }^{10}$ therefore, when medical students read through our journals, the lack of works authored by women may perpetuate the male-dominated field image and may understandably discourage talented female candidates. While our profession manages to decrease the gender gap in prominent neurosurgical authors, strategies such as dedicating a specific journal issue to women in neurosurgery may help to highlight the accomplishments and successes of female neurosurgeons, thus providing an easier way to find several outstanding role models at once.

Mentorship has also been one of the factors that is frequently studied because of its large influence in women's career advancement. ${ }^{10,13,29-34}$ Interestingly, the present data showed that when the senior author of an article was a woman, female first authorship increased to almost $30 \%$, compared with the $12 \%$ when the senior author was a man.

TABLE 3. Advanced degree versus research productivity by gender

\begin{tabular}{|c|c|c|c|c|c|c|c|c|c|}
\hline & \multicolumn{3}{|c|}{$M D$} & \multicolumn{3}{|c|}{$\mathrm{MD}, \mathrm{PhD}$} & \multicolumn{3}{|c|}{ Non-MD } \\
\hline & Female & Male & p Value & Female & Male & $p$ Value & Female & Male & $\mathrm{p}$ Value \\
\hline 1st author & 99/184 (53.8) & $823 / 1144$ (71.9) & 0.001 & 15/184 (8.2) & $179 / 1144(15.6)$ & 0.008 & 70/184 (38.4) & $142 / 1144(12.4)$ & 0.001 \\
\hline Senior author & $51 / 97(52.6)$ & $822 / 1231(67.7)$ & 0.005 & 23/97 (23.7) & $345 / 1231$ (28.1) & 0.361 & $22 / 97(22.7)$ & $56 / 1231(4.5)$ & 0.001 \\
\hline
\end{tabular}

Values are presented as the number of authors/total number (\%) unless indicated otherwise. 
These findings are in line with previous literature suggesting that male faculty, in general, but especially those considered elite researchers (with more high-impact publications, funding, and awards), mentor significantly fewer women than their female counterparts. ${ }^{35}$ Milkman et al. also demonstrated that male faculty are less likely to respond to inquiring female students than to male students, ${ }^{36}$ and Moss-Racusin et al. showed different ratings to the same student curriculum vitae by randomly changing the name from a male name to a female name ${ }^{37}$ However, the causes behind this skewed mentoring pattern may be not only a bias on the senior authors' side but also an issue of self-selection among female students or trainees. Unconscious bias may lead women to underrate their own abilities $^{38-41}$ and may therefore prevent them from applying to junior research positions or seeking elite mentors' guidance. Unconscious implicit bias may take decades to change, as new generations raised with different cultural norms arrive to our profession. Meanwhile, initiatives like the mentoring program from the Women in Neurosurgery (WINS) association ${ }^{9}$ may help connect aspiring women with appropriate willing mentors who may help them advance in their academic career.

\section{Trends in Female Authorship}

Another intriguing finding of our research is the trend in female authorship during the study period. While overall numbers showed a significant increase in both first and senior authors, when singling out the regions, we found that the number of women serving as authors in Europe has not changed over the past decade. The US and Canada had a lower initial percentage of both first and senior female authors in 2009, which has increased to what would be expected given the regions' statistics on new recruitments. Europe, on the other hand, may have experienced a significant initial increase a few years earlier and has now reached a plateau at approximately $20 \%$ for female junior authors and $10 \%$ for female senior authors. Further investigation on previous and future time trends in both regions is warranted to better understand the real causes behind these data. However, this worrisome finding may suggest that the authorship trend during the past decade in the US/Canada has mirrored the trend that Europe might have experienced a decade earlier. If the mirroring continues, the US and Canada would also show a stagnant trend in the next decade. Therefore, without specific and active measures, the gender gap may not improve beyond the average $10 \%$ of senior female neurosurgical researchers already achieved in Europe. Previous studies on gender inequity have reported similar findings suggesting that highly male-dominated surgical specialties have a lower and harder-to-break glass ceiling that translates into poorer rates of improvement in gender imbalance over time. ${ }^{16}$ Most likely, a percentage below $15 \%$ represents a percentage of individuals not large enough to function as a minority group ${ }^{21}$ and to provoke changes on their own, thus perpetuating the feared pipeline effect. Aggressive measures to counteract this pipeline effect were already suggested more than a decade ago by several landmark papers on gender inequity in neurosurgery. ${ }^{9,12,13}$ We should now evaluate what needs to be done differently to achieve the unmet goal of $20 \%$ female facul- ty that the WINS White Paper proposed for the year $2020^{9}$ and that may represent the tipping point toward a faster yet solid evolution to gender parity.

\section{Differences in Researchers' Profiles}

The differences we found in terms of profile between female and male researchers are also concerning. According to the data, only $3.6 \%$ (48/1328) of senior authors identified in the most prestigious neurosurgical journals were women who held MDs or MD/PhDs and were affiliated with a neurosurgical department; therefore, most female senior authors were not neurosurgeons. One possible explanation is that the pool of female academic neurosurgeons, from which senior authors would come, remains quite low. A recent report by Odell et al. found that the overall number of women in academic neurosurgery in the US and Canada was 12\%, but at the full professor level, the percentage dropped to $5.8 \%,{ }^{4}$ which represents the second lowest percentage of female professors in a specialty, after orthopedic surgery. ${ }^{7}$ Furthermore, several studies have also demonstrated that female faculty receive fewer resources in terms of funding opportunities, assistance staff, allocation of space, etc., which would most likely influence their productivity. ${ }^{42,43}$ Also, previous literature suggests that female faculty devote more time to clinical activities and teaching than to research, ${ }^{44,45}$ which may explain the lower number of published articles. Finally, some studies have found that, even after correcting for confounding factors, female faculty publish less than half the number of articles published by male faculty. ${ }^{46} \mathrm{In}$ short, the marginal number of female neurosurgeons found among the senior authors of our journals might be due to a multifactorial and complex problem. An overall increase in the number of female academic neurosurgeons should eventually translate into a higher percentage of female authorship in scientific publications. But in the meantime, strategies to best support the existing female faculty may improve women visibility in our journals. As proposed by Abosch and Rutka, ensuring an editing and review process free of unconscious bias (double blinded), fostering gender equity in editorial boards, and implementing gender targets for invited articles may help portray a landscape closer to gender equity in our journals. ${ }^{8}$ This would hopefully have a ripple effect: bright female candidates would find successful examples of what they could achieve, hence encouraging them to follow a career in neurosurgery.

\section{Limitations}

Our work has several limitations worth mentioning. First, the journals selected for the investigation are among the most prestigious within the specialty and have a high impact factor, which, according to previous research, may have negatively affected the number of women submitting and publishing their research in them..$^{16,47}$ Although this may have underestimated the percentage of women in leading neurosurgical research roles, the study design still allowed for an understanding of the picture of gender diversity that potential new recruitments are exposed to when reading these most outstanding journals. Second, given names of researchers from Asian descent proved 
to be the hardest to decipher and caused the most losses due to undetermined gender. Although this may have underrepresented the overall number of Asian authors, one should expect this underrepresentation to be equally distributed among genders, thus not affecting the percentages. Third, the email sent to the corresponding authors specifically stated that this was a study about the role of gender in neurosurgical research and was sent by the senior author, who is a woman; thus, female corresponding authors might have been more likely to respond. Nevertheless, this represented less than $1 \%$ of the data, which may minimize the impact of this likely bias. Finally, the research was designated to count the number of times an article had a woman in the first or senior author role; therefore, it is possible that some of these women are repeated through the sample, thus diminishing the real number of outstanding female role models available for the younger generation. Nevertheless, the aim of understanding the representation of gender distribution that likely neurosurgical candidates get through our most outstanding journals should not be affected by this flaw.

\section{Conclusions}

Continuous tracking of statistics on gender distribution in our specialty is paramount to develop the appropriate strategies to ensure a more equitable neurosurgical model that fosters diversity and keeps attracting the best and the brightest candidates to our field. As a driving force of our profession and an exposure window to medical students who might be considering a career in neurosurgery, research publications should portray enough outstanding female role models and an underlying message of welcoming talented women to the specialty. Although our data showed that the number of women publishing high-impact neurosurgical research has significantly increased in the past decade, some worrisome traits warrant a closer followup. In Europe, a region with an initial higher percentage of female authors, the past 10-year trend is stagnant, which may suggest that a glass ceiling has been reached there and further advances in equity would require more aggressive measures. Furthermore, this investigation showed clear differences in the researchers' profiles according to gender, which may reinforce previous literature suggesting that academic neurosurgery has a wider gender gap than other specialties. Finally, implicit cultural bias, most likely coming from both men and women, may explain why female senior authors have more than double the number of women serving as their junior authors than their male counterparts. This implicit cultural bias may take generations to change, but strategies such as publishing specific journal issues or sections on women, prioritizing editorials and invited submissions by women, and working toward more gender-balanced editorial boards may help in the direction of portraying in our journals a more equitable specialty that does not discourage bright female candidates.

\section{References}

1. Gilkes CE. An account of the life and achievements of Miss Diana Beck, neurosurgeon (1902-1956). Neurosurgery. 2008; 62(3):738-742.
2. Ciurea A-V, Moisa HA, Mohan D. Sofia Ionescu, the first woman neurosurgeon in the world. World Neurosurg. 2013; 80(5):650-653.

3. Kim EE, Klein AL, Lartigue JW, et al. Diversity in neurosurgery. World Neurosurg. 2021;145:197-204.

4. Odell T, Toor H, Takayanagi A, et al. Gender disparity in academic neurosurgery. Cureus. 2019;11(5):e4628.

5. Steklacova A, Bradac O, de Lacy P, Benes V. E-WIN Project 2016: evaluating the current gender situation in neurosurgery across Europe-an interactive, multiple-level survey. World Neurosurg. 2017;104:48-60.

6. Dixon A, Silva NA, Sotayo A, Mazzola CA. Female medical student retention in neurosurgery: a multifaceted approach. World Neurosurg. 2019;122:245-251.

7. Renfrow JJ, Rodriguez A, Wilson TA, et al. Tracking career paths of women in neurosurgery. Neurosurgery. 2018;82(4): 576-582.

8. Abosch A, Rutka JT. Women in neurosurgery: inequality redux. J Neurosurg. 2018;129(2):277-281.

9. WINS White Paper Committee; Benzil DL, Abosch A, Germano I, et al. The future of neurosurgery: a white paper on the recruitment and retention of women in neurosurgery. $J$ Neurosurg. 2008;109(3):378-386.

10. Wolfert C, Rohde V, Mielke D, Hernández-Durán S. Female neurosurgeons in Europe-on a prevailing glass ceiling. World Neurosurg. 2019;129:460-466.

11. Kato Y, Mihara C, Matsuyama J, et al. Role of women in medicine: a look at the history, the present condition and the future status of women in the surgical field, especially neurosurgery. Minim Invasive Neurosurg. 2004;47(2):65-71.

12. Spetzler RF. Progress of women in neurosurgery. Asian J Neurosurg. 2011;6(1):6-12.

13. Woodrow SI, Gilmer-Hill H, Rutka JT. The neurosurgical workforce in North America: a critical review of gender issues. Neurosurgery. 2006;59(4):749-758.

14. Bates C, Gordon L, Travis E, et al. Striving for gender equity in academic medicine careers: a call to action. Acad Med. 2016;91(8):1050-1052.

15. Asplund M, Welle CG. Advancing science: how bias holds us back. Neuron. 2018;99(4):635-639.

16. Holman L, Stuart-Fox D, Hauser CE. The gender gap in science: how long until women are equally represented? PLoS Biol. 2018;16(4):e2004956.

17. Wilkes FA, Akram H, Hyam JA, et al. Publication productivity of neurosurgeons in Great Britain and Ireland. J Neurosurg. 2015;122(4):948-954.

18. Khan NR, Thompson CJ, Taylor DR, et al. An analysis of publication productivity for 1225 academic neurosurgeons and 99 departments in the United States. J Neurosurg. 2014; 120(3):746-755.

19. Tomei KL, Nahass MM, Husain Q, et al. A gender-based comparison of academic rank and scholarly productivity in academic neurological surgery. J Clin Neurosci. 2014;21(7): $1102-1105$.

20. Ausman JI, Epstein N, West JL. Comparative metrics of neurosurgical scientific journals: what do they mean to readers? Surg Neurol Int. 2020;11:169.

21. Etzkowitz H, Kemelgor C, Neuschatz M, et al. The paradox of critical mass for women in science. Science. 1994; 266(5182):51-54.

22. Jagsi R, Guancial EA, Worobey CC, et al. The "gender gap" in authorship of academic medical literature-a 35-year perspective. N Engl J Med. 2006;355(3):281-287.

23. Neumayer L, Kaiser S, Anderson K, et al. Perceptions of women medical students and their influence on career choice. Am J Surg. 2002;183(2):146-150.

24. Zarebczan B, Rajamanickam V, Lewis B, et al. The impact of the 80-hour work week on student interest in a surgical career. J Surg Res. 2011;171(2):422-426. 
25. Lockwood P. "Someone like me can be successful": do college students need same-gender role models? Psychol Women Q. 2006;30(1):36-46.

26. Mayer KL, Perez RV, Ho HS. Factors affecting choice of surgical residency training program. J Surg Res. 2001;98(2): 71-75.

27. Wright SM, Carrese JA. Serving as a physician role model for a diverse population of medical learners. Acad Med. 2003; 78(6):623-628.

28. Sarkiss CA, Riley KJ, Hernandez CM, et al. Academic productivity of US neurosurgery residents as measured by H-index: program ranking with correlation to faculty productivity. Neurosurgery. 2017;80(6):975-984.

29. Yedidia MJ, Bickel J. Why aren't there more women leaders in academic medicine? The views of clinical department chairs. Acad Med. 2001;76(5):453-465.

30. Sambunjak D, Straus SE, Marusić A. Mentoring in academic medicine: a systematic review. JAMA. 2006;296(9):11031115.

31. Ogunyemi D, Solnik MJ, Alexander C, et al. Promoting residents' professional development and academic productivity using a structured faculty mentoring program. Teach Learn Med. 2010;22(2):93-96.

32. McCord JH, McDonald R, Sippel RS, et al. Surgical career choices: the vital impact of mentoring. J Surg Res. 2009; 155(1):136-141.

33. Venes JL, Parent AD. Women in neurological surgery. Matson Memorial Lecture. J Neurosurg. 2006;104(4)(suppl): 227-232.

34. Renfrow JJ, Rodriguez A, Liu A, et al. Positive trends in neurosurgery enrollment and attrition: analysis of the 20002009 female neurosurgery resident cohort. J Neurosurg. 2016;124(3):834-839.

35. Sheltzer JM, Smith JC. Elite male faculty in the life sciences employ fewer women. Proc Natl Acad Sci U S A. 2014; 111(28):10107-10112.

36. Milkman KL, Akinola M, Chugh D. What happens before? A field experiment exploring how pay and representation differentially shape bias on the pathway into organizations. J Appl Psychol. 2015;100(6):1678-1712.

37. Moss-Racusin CA, Dovidio JF, Brescoll VL, et al. Science faculty's subtle gender biases favor male students. Proc Natl Acad Sci U S A. 2012;109(41):16474-16479.

38. Lind DS, Rekkas S, Bui V, et al. Competency-based student self-assessment on a surgery rotation. J Surg Res. 2002; 105(1):31-34.

39. Minter RM, Gruppen LD, Napolitano KS, Gauger PG. Gender differences in the self-assessment of surgical residents. Am J Surg. 2005;189(6):647-650.

40. Steinmayr R, Spinath B. What explains boys' stronger confidence in their intelligence? Sex Roles. 2009;61(9-10):736-749.
41. Correll SJ. Gender and the career choice process: the role of biased self-assessments. AJS. 2001;106(6):1691-1730.

42. Tesch BJ, Wood HM, Helwig AL, Nattinger AB. Promotion of women physicians in academic medicine. Glass ceiling or sticky floor? JAMA. 1995;273(13):1022-1025.

43. Nonnemaker L. Women physicians in academic medicine: new insights from cohort studies. $N$ Engl J Med. 2000;342(6): 399-405.

44. Buckley LM, Sanders K, Shih M, et al. Obstacles to promotion? Values of women faculty about career success and recognition. Committee on the Status of Women and Minorities, Virginia Commonwealth University, Medical College of Virginia Campus. Acad Med. 2000;75(3):283-288.

45. Astin HS, Cress CM. A national profile of academic women in research universities. In: Hornig LS, ed. Equal Rites, Unequal Outcomes. Innovations in Science Education and Technology. Vol 15. Springer Netherlands; 2003:53-88.

46. Schroen AT, Brownstein MR, Sheldon GF. Women in academic general surgery. Acad Med. 2004;79(4):310-318.

47. Knobloch-Westerwick S, Glynn CJ, Huge M. The Matilda effect in science communication: an experiment on gender bias in publication quality perceptions and collaboration interest. Sci Commun. 2013;35(5):603-625.

\section{Disclosures}

The authors report no conflict of interest concerning the materials or methods used in this study or the findings specified in this paper.

\section{Author Contributions}

Conception and design: Rodríguez-Hernández, Torné. Acquisition of data: Rodríguez-Hernández, Pastor-Cabeza. Analysis and interpretation of data: Rodríguez-Hernández, Pastor-Cabeza, Torné, Bollar, Sarabia. Drafting the article: Rodríguez-Hernández. Critically revising the article: all authors. Reviewed submitted version of manuscript: all authors. Approved the final version of the manuscript on behalf of all authors: Rodríguez-Hernández. Statistical analysis: Torné. Administrative/technical/material support: Pastor-Cabeza, García-Armengol, Menéndez-Osorio, Mosteiro-Cadaval. Study supervision: Rodríguez-Hernández.

\section{Correspondence}

Ana Rodríguez-Hernández: Germans Trias i Pujol University Hospital, Universidad Autónoma de Barcelona, Badalona, Barcelona, Spain. ana.neurosurgery@hotmail.com. 